\title{
A Review on the epidemiology and characteristics of COVID-19
}

\author{
Ranjit Barua ${ }^{1, *}$, Sudipto Datta1, Amit RoyChowdhury ${ }^{1,2}$, Pallab Datta 3 \\ ${ }^{1}$ Centre for Healthcare Science and Technology, Indian Institute of Engineering Science and Technology, Shibpur, Howrah 7111o3, \\ West Bengal, India \\ ${ }^{2}$ Department of Aerospace Engineering and Applied Mechanics, Indian Institute of Engineering Science and Technology, Shibpur, \\ Howrah 711103, West Bengal, India \\ 3National Institute of Pharmaceutical Education and Research, Kolkata, Kolkata, India
}

\begin{abstract}
In December 2019, there was a health emergency worldwide named novel coronavirus or COVID-19 by the world health organization (WHO). It originated from the Wuhan seafood market, Hubei Province, China. Till now Severe Acute Respiratory Syndrome Coronavirus-2 or SARS-CoV-2 spread over 216 countries with 177,108,695 confirmed cases and 3,840,223 confirmed death cases has been reported (5:31 pm CEST, 18 June 2021; WHO). Analyzing the risk factor of this pandemic situation, different government health organizations of all the countries including WHO are taking several preventive measures with ongoing research works, even the vaccination process started. In this study, we tried to analyze all the available information on pandemic COVID-19, which includes the origin of COVID-19, pathogenic mechanism, transmission, diagnosis, treatment, and control-preventive measures, also the additional treatment and prevention taken by the Indian government is being studied here.
\end{abstract}

Keywords: SARS-CoV-2, WHO, Outbreak, Pathogenic Mechanism, India

\section{Introduction}

In December 2019, World Health Organization (WHO) was reported unknown symptoms of pneumonia cases by the Chinese Health Authority in Wuhan City in Hubei Province, China. It was reported that most of the patients with positive cases were connected to the Wuhan seafood wholesale market [1]. WHO named it the novel coronavirus or 2019-nCoV on 7th January 2020 [2]. It was identified from the swab test sample of patients. Later, the coronavirus Study Group and WHO renamed it as severe acute respiratory syndrome coronavirus-2 (SARS-CoV-2) [3]. On 30th January 2020, China reported 79,394 confirmed cases and 12,167 suspected cases; more than 82 confirmed cases were reported from eighteen other countries [4]. On the same day, WHO declared it as a worldwide pandemic emergency [5]. Initially,
National Health Commission (China) reported to WHO that inside of China the mortality rate was $2.1 \%$, whereas the outside of China was reported with a $0.2 \%$ mortality rate (4th Feb 2020) [6]. Among the admitted patients, the mortality rate was between 11\%-15\% [7]. Coronavirus disease 2019(COVID-19) was reported as a highly infectious disease with a higher spreading rate than the mortality rate [8]. This study aimed to analyze the available information of pandemic COVID-19 including pathogenic mechanism, transmission, diagnosis, treatment, and control-preventive measures.

\subsection{Origin and cataloging of COVID-19}

The analysis of the genome sequence of SARS$\mathrm{CoV}-2$ reveals the whole genome sequence recognition rates of bat SARS coronavirus (SARSr-CoV-RaTG13)

\section{"Corresponding author:}

Ranjit Barua, Ph.D

Centre for Healthcare Science and Technology, Indian Institute

of Engineering Science and Technology, Shibpur, Howrah 711103, West Bengal, India

(C) The Author(s) 2021

Tel/Fax: +91 8910642686

Email: ranjitjgecoo7@gmail.com

https://orcid.org/oooo-0003-2236-3876

Received: May, 29, 2021

Accepted: June, 21, 2021 
was $96 \%$ whereas SARS-CoV was $79.5 \%$ [9]. This shows that COVID-19 might have their origination from bats. Gradually the rate of active cases is increasing [10]. SARS-CoV-2 is a family member of Coronaviridae and the order Nidovirales. The family is subdivided into Torovirinae and Coronaviridae, furthermore, Coronaviridae is divided into four categories: (I) $\alpha$-coronavirus consists of human coronavirus (HCoV-229E and $\mathrm{HCoV}-\mathrm{NL} 63)$; (II) $\beta$ coronavirus consists of SARS-HCoV (Severe Acute Respiratory Syndrome), HCoV-OC43, MERS-CoV (Middle-Eastern Respiratory Syndrome Coronavirus); (III) $\gamma$-coronavirus consists of the viruses for birds and whales; (IV) $\delta$-coronavirus [11]. SARS-CoV-2 originated from $\beta$-coronavirus combined with two highly pathogenic viruses MiddleEastern respiratory syndrome coronavirus (MERS$\mathrm{CoV}$ ) and severe acute respiratory syndrome (SARS$\mathrm{HCoV}$ ), respectively [12]. The phylogenetic analysis of novel coronavirus or SARS-CoV-2 shows that the connection of the virus is linked with two different viruses (88\% related) which derive from the bat, batSL-CoVZXC21, and bat-SL-CoVZC45, respectively which genetically differs from MERS-CoV and SARS$\mathrm{CoV}$ [13]. Further research work with the help of genome sequences of RaTG13, SARS-CoV, and SARS$\mathrm{CoV}-2$ shows that the virus is associated with Bat $\mathrm{CoV}$ RaTG13 which was previously found in Rhinolophusaffinis from Wuhan Province (overall 96\% genome sequence) [14]. No evidence of recombination was found in the genome of a novel coronavirus from other viruses which originated from bats liked $\mathrm{Bat} \mathrm{CoV}$ RaTG13, SARS-CoV. Further studies suggest that the origin of this virus is from the bat family [13]. Although, a related study is going on if there was any mediator via which the virus was transmitted to human bodies. Reasons which shows that bats are not solely responsible for the human transmission of coronavirus are as follows: (i) availability of several non-aquatic animals which also consists of mammals for selling in Wuhan seafood market but there was no sign of bats; (ii) novel coronavirus and its neighbors bat-SL-CoVZXC21 and bat-SL-CoVZC45 which have a comparatively long branch (less than $90 \%$ sequence identity), recommends that those viruses have no direct connection with SARS-CoV-2; (iii) other animals (civets, most probably camels respectively) acted as a mediator where the bat is the host in the coronavirus cases like MERS-CoV and SARS-CoV
[14]. Basically, coronavirus consists of single-stranded RNA viruses with a diameter of $80-120 \mathrm{~nm}$. It can be categorized into four types- (i) $\alpha$-coronavirus; (ii) $\beta$ coronavirus; (iii) $\gamma$ - coronavirus; and (iv) $\delta$ coronavirus [15]. Figure 1 shows the various types of coronavirus. Other than SARS-CoV-2, more than six coronaviruses including MERS-CoV and SARS-CoV have been identified before. The homology of SARS$\mathrm{COV}$ and SARS-CoV-2 in the genome sequence is roughly $79 \%$; which is similar to SARS-like bat coronavirus (MG772933) [16, 17].



Figure 1. Various categories of coronavirus

\subsection{COVID-19 pathogenic mechanism}

Several studies show that novel coronavirus uses the ACE2 which is known as the "Angiotension Converting Enzyme-2" receptor, which is similar to SARS-CoV [18]. This virus mostly knows it's consistent that targets the upper layer of the cells by the by $\mathrm{S}$ proteins (Figure 2a); which results in infection. A study indicates that novel coronavirus fixes to ACE2 with more than ten folds higher similarity than SARS-CoV, the stage beyond the inception needed for virus contagion [19]. The complete process through which COVID-19 affects humans by fixing spike protein to ACE2 shows in Figure 2b, the strong point of the contact for the threat of human transmission, and how this virus causes organ failure is still unknown. These outcomes describe the quicker transmission ability of novel coronavirus in humans as related to SARS-CoV, and 

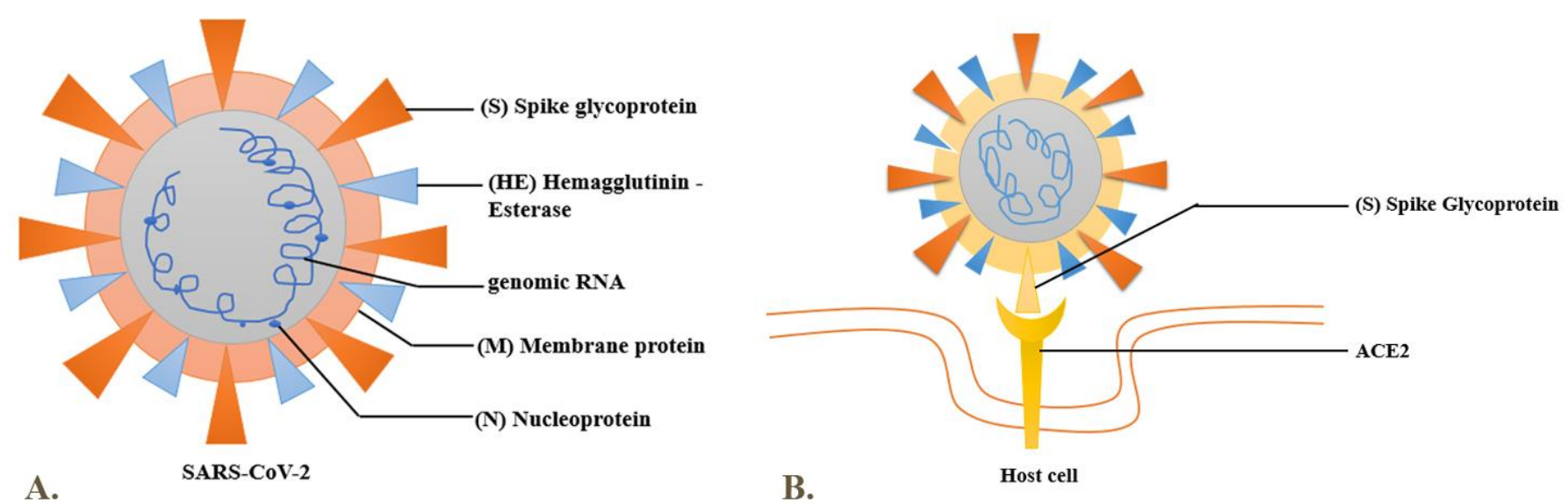

Figure 2. A. Genome structure of SARS-CoV-2; B. SARS-CoV-2 infects the host cell

the most number of confirmed cases of SARS-CoV-2 as associated with the infection of SARS-CoV. Since the most similarity of novel coronavirus fixes to ACE2, this receptor can be a possible applicant for the cure of novel coronavirus [20].

\subsection{Transmission of SARS-CoV-2}

The spreading of coronavirus or SARS-CoV-2 by the Wuhan seafood market is still not clear. Initially, it was said that the novel corona virus-positive incidents were associated with this marketplace (animal to human transmission) [21]. Genomic research has delivered such evidence which shows the virus was originated from an unidentified place in the market, where it has spread nearer, however it was noticed that the transmission from human to human has happened previously [22]. The human-to-human transmission has been confirmed by the infected family members and health workers [23]. It was reported after 1st January that only $10 \%$ of the positive cases were related to the Wuhan seafood market and more than $70 \%$ of the patients were not related to that market [21]. It was predicted that human transmission happens in close contact especially through respiratory droplets originate from an infected persons' sneezes and coughs. It was found that SARS$\mathrm{CoV}$ and other coronaviruses can stay on the surfaces for up to $96 \mathrm{hrs}$ and 9 days, respectively [24, 25].

On 3oth January 2020, an asymptomatic transmission was reported [26], but by the researchers, no direct interview of the patient was reported, who had symptoms of transmission of disease [27]. An asymptomatic transmission was reported on 21st February 2020 [28]. The mean incubation period was reported to be 5.2 (95\% CI: 4.17.0) days [16]. This period can be elongated to 19 or 24 days [29, 30], however, the case descriptions usually depend on a fourteen days window [31]. Also, reproductive number (Ro) is predicted with fluctuating outcomes and analyses. It also measures the typical number of infected cases which results in one infected case to the whole population [32]. Figure 3 shows the transmission of coronavirus. Previous studies found reproductive number (Ro) is to be 2.7 and 2.4 for SARS [33], and 2009 pandemic H1N1 influenza [34]. Another study predicted that the reproductive number (95\% CI: 1.4-3.9) was 2.2 [13]. Although, further studies suggested the reproductive number (Ro) to be 3.28 [35]. Normally reproductive number (Ro) represents the typical value which is considered to be the sole transmitter, which is most responsible for the spreading of epidemics in large groups [36]. In a severe case like epidemic or pandemic, reproductive number (Ro) is unstable [32]. There is a risk of transmission if a pregnant woman is admitted to the hospital but no such maternal and fetal casualty, and vertical utero-transmission were noticed [37]. Currently, 177,108,695 confirmed cases and 3,840,223 confirmed death cases have been reported [5:31 pm CEST, 18 June 2021; WHO] (Supplementary Figure 1). The confirmed cases of the individual countries affected by COVID-19 are given in descending (high to low) order in supplementary Table 1. 


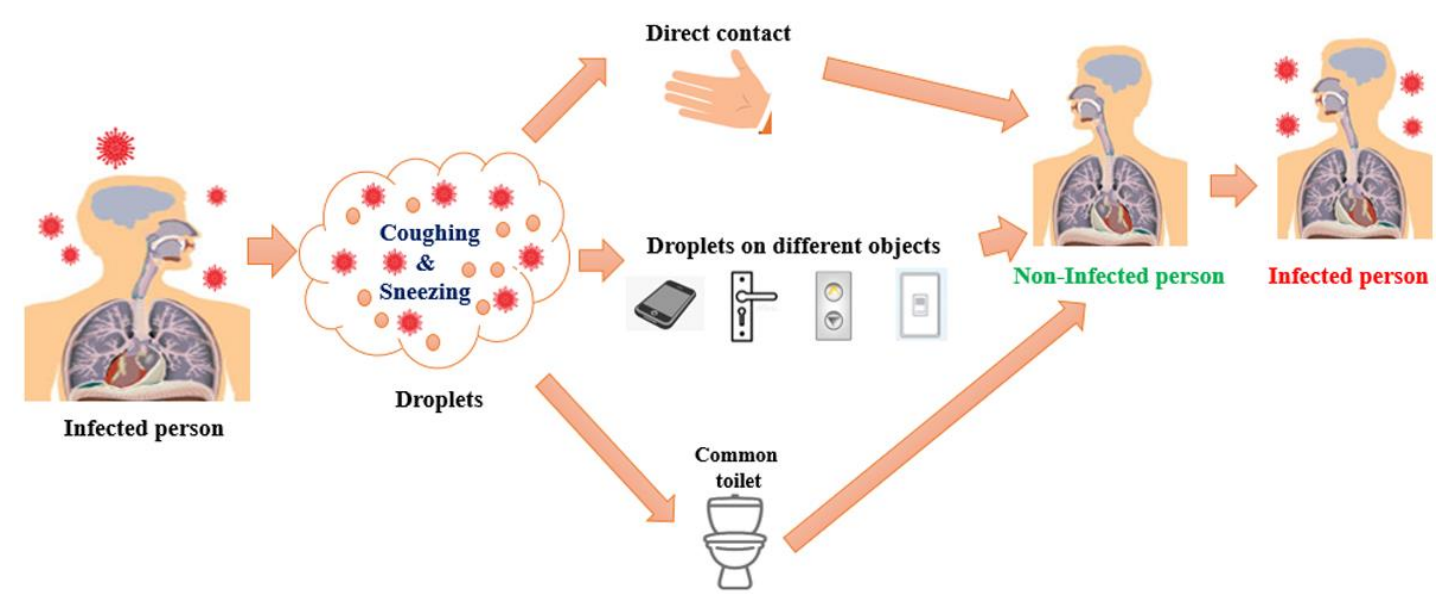

Figure 3. Transmission routes of coronavirus

\subsection{The epidemiology of novel coronavirus}

On 3rd March 2020, a total of 87,317 positive cases has been confirmed by WHO. Among all the definite cases, about 2,977 cases have yielded to the virus. The common symptoms and demises are informed by China. From the entire figure of positive cases, 79,968 infected patients have been recognized in China [38]. The common symptoms and demises are informed by China. From the entire figure of positive cases, 79,968 infected patients have been recognized in China [39]. It has been found that the clinical characteristics of 1,099 numbers of COVID- 19 patients, where the median incubation period time was approximately 3 days, basically the range is $0-24$ days, the average period from the development of the symptoms to death was approximately 14 days [40]. For SARS-CoV septicity, the median expectancy was four days, the typical intermission from indication beginning to the taken to hospital was three days, and the usual interim from hospital entry time to death was seventeen days [41]. The median expectancy of the infection of MERS-CoV was seven days. The average development period for novel coronavirus is smaller than that for MERS and SARS, respectively. Conversely, the maximum expectancy of novel coronavirus currently detected is as high as twentyfour days, which may raise the threat of virus transmission. Furthermore, persons aged more than seventy years had a shorter medium interval approximately eleven days from the indication start to death associated with patients aged less than seventy years, signifying that infection progress is speedier in aged persons related with elder persons [38, 42].

\subsection{Risk factors of COVID-19}

The cases of SARS-CoV-2 septicity are realized most frequently in mature man patients with the middle age of the peoples was between thirty-four and fifty-nine years old [43, 44]. The novel coronavirus is also more likely to contaminate people with lifelong diseases like cerebrovascular and diabetes diseases, respectively [45]. The maximum amount of severe problems happens in mature ages more than sixty years, and with assured essential circumstances, for example, diabetes, cerebrovascular and cardiovascular diseases, respectively [46]. Severe appearances may be also connected with infected bacteria and fungi respectively. Also, below 15 years of age lower number of COVID-19 cases are reported [47]. Figure 4 shows the effect of coronavirus on the human body. A recent study published on Jan 29th stated that among 425 patients of COVID-19 cases in Wuhan, China no cases were reported below 15 years of age [48]. The medical features of the pediatric infected patients were different, and the majority of patients had mild symptoms, having no low-grade fever and or pneumonia along with a good prognosis. Another report stated that though a kid had ground-glass radiological lung denseness, while the patient showed no symptoms [49]. From this, the conclusion that can be made is that children are less likely to get an infection than adults. Also, if infection occurs in children mild manifestations are shown than adults which can lead to no treatment of their parents because of underestimate COVID-19 symptoms in that age range. 


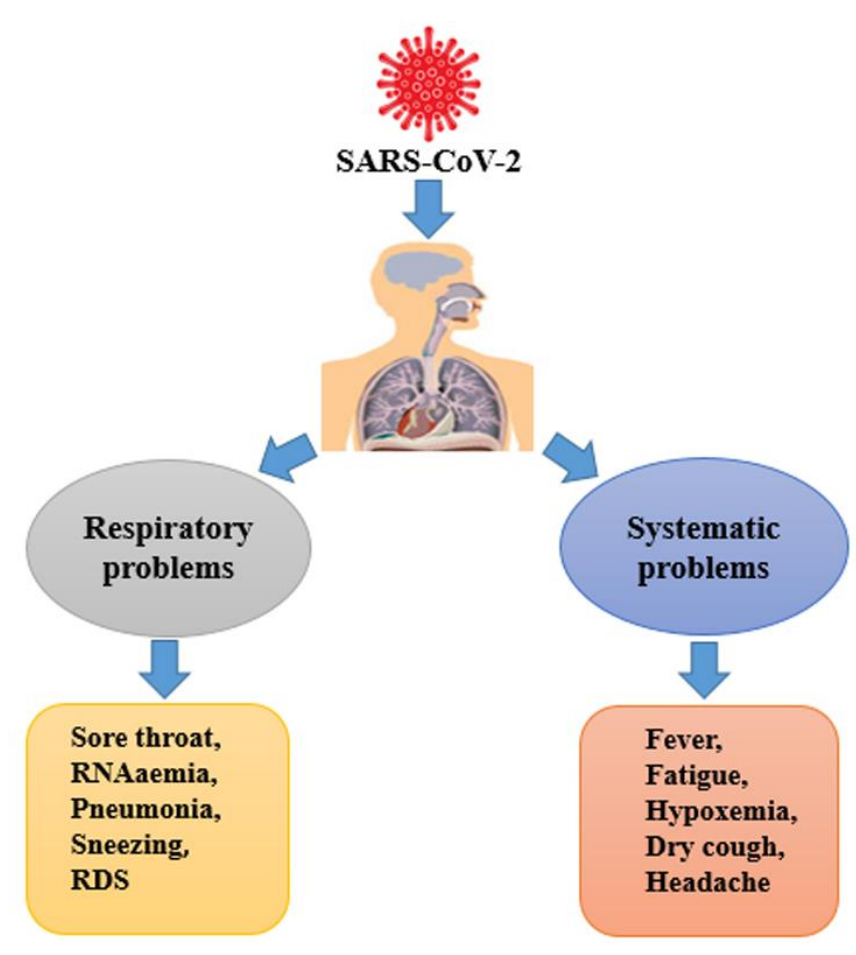

Figure 4. Effects of COVID-19 on human

\subsection{Clinical features}

Novel coronavirus generates an acute viral infection in patients with a middle incubation period of 3 days [48]; which is related to SARS, with two to ten days of incubation period [49]. The main signs of novel coronavirus are cough, fever, fatigue, and diarrhea, respectively [50], like other coronavirus symptoms. Many positive patients had an appearance of some degree of dyspnea; the intermission from indication start to the appearance of severe respiratory distress syndrome which was only nine days within the initial cases [51]. Moreover, severe cases are prone to a variety of complications, including secondary infection, and acute respiratory distress syndrome [52]. Based on the report in Wuhan's first 425 detected cases, the mutual indications contain fever, dry cough, myalgia, and fatigue with fewer normal are headache, hemoptysis, sputum production, diarrhea, and abdominal [21]. Nearly $75 \%$ of patients had bilateral pneumonia [53]. Unalike from MERS-CoV and SARSCoV symptoms, SARS-CoV-2 less likely indicate projecting upper respiratory tract marks and sore throat, sneezing, signifying that the virus might have a better tendency for contaminating the lower respiratory tract [54]. It is reported that pregnant women may have fewer COVID-19 symptoms than non-pregnant women but should take intensive care if severely infected [55]. Some reports also state that novel coronavirus can be harmful to organs and tissues other than the lungs. Another study states that out of 214 positive patients 78 patients had neurological symptoms [56]. Additionally, there is evidence SARS-CoV-2 RNA was detected in eye secretions of patients [57]. Computerized tomography (CT) scan is an essential tool to identify this pneumonia. Numerous usual imaging topographies are normally detected in novel coronavirus pneumonia, as well as $50 \%$ of leading ground-glass consolidations, $65 \%$ of opacity, $35 \%$ of a plane or unequal interlobular septal thickening, $47 \%$ of lower lobe involvement air bronchograms, predominantly peripheral and $32 \%$ of condensing of the adjacent pleura [58]. A current study described that $90 \%$ of patients had bilateral chest CT scan report results, and the understanding of chest CT scan report to suggest 97\% of novel coronavirus [59]. Merging CT scan reports with clinical indication and laboratory results could allow initialing medicare treatment of pneumonia of novel coronavirus.

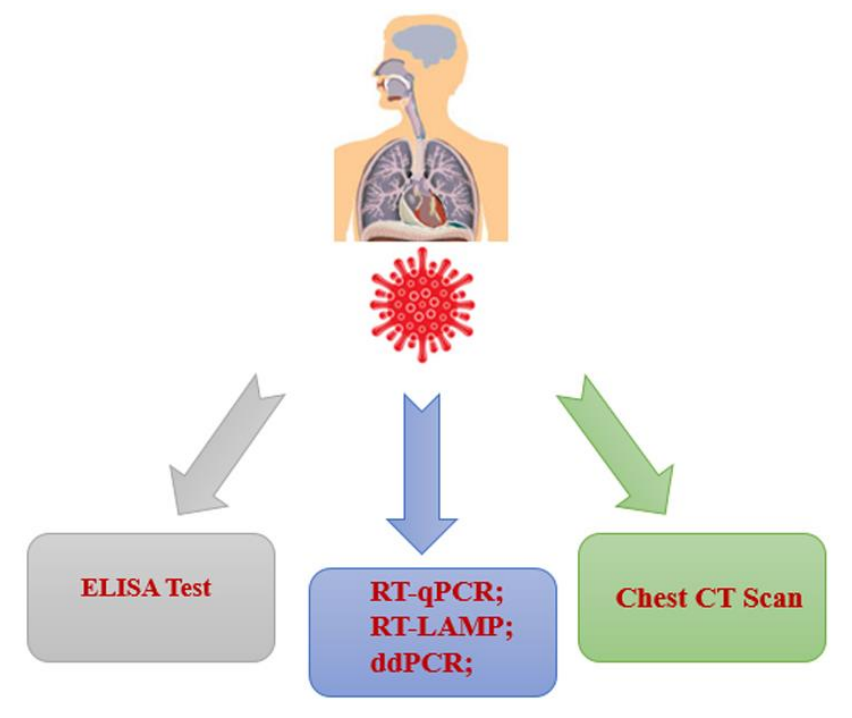

Figure 5. Different diagnoses process of COVID-19

\subsection{Diagnosis}

The WHO endorses gathering samples from lower as well as upper respiratory tracts. This can be attained by endotracheal aspirate, expectorated sputum, and bronchoalveolar lavage [59]. These models are then evaluated for viral RNA by polymerase chain reaction (PCR). When a positive result comes retest on the 


\section{Barua et al.}

sample should be done and if negative comes a retest is also done for confirmation. The recognition of viral nucleic acid is normal for the non-invasive analysis of the novel COVID-19. Figure 5 shows the various diagnosis process of COVID-19.

\subsection{Treatment}

Currently like the previous coronaviruses SARS$\mathrm{CoV}$ and MERS-CoV there is no specific treatment for COVID-19. Supportive care like fluid management, oxygen therapy, antibiotic treatment of the bacterial secondary infection, and isolation are suggested [6o]. Few cases of COVID-19 patients advance quickly to septic shock and acute respiratory distress syndrome (ARDS) which leads to multiple organ failure [61]. So it is very much important to stop the spread of the disease by infection control measures and isolating the patient and providing necessary treatments for recovering from the disease [62]. Currently, COVID-19 patient treatments are commonly symptomatic. For this kind of RNA coronaviruses Remdesivir an antiviral drug showed positive results in most cases. In a report, Holshue et al. stated that Remdesivir shower good results on many patients of COVID-19 [63]. A drug for treating malaria, Chloroquine has been found to show the activity of immune-modulatory and has shown an antiviral effect on SARS-CoV-2 in vitro. In the clinic also it is seen that the drug Chloroquine showed positive results [64]. Currently, the drug Remdesivir is also being used on the COVID-19 patients till now the drug efficacy is unknown [65]. Influenza viruses fusion were been blocked by a molecule Umifenovir (trade name Arbido) which is a small indole-derivative molecule. Recently it has been suggested that Umifenovir can help fight against COVID-19 [66]. If sepsis is recognized, antibiotics of empiric type should be directed depending on clinical diagnosis and susceptibility information, and local epidemiology. Daily glucocorticoid direction is not suggested if there are additional signs [67]. Usage of intravenous immunoglobulin could be helpful for extremely ill patients. Drug evaluation in line with past inquiries into the treatments for therapeutic in MERS and SARS [68]. Though there is no proof that these drugs can improve the patient's condition clinically. An empirical antibiotic treatment combined with antiviral drug Oseltamivir was employed for treating COVID-19 cases [71]. In the USA Ebola antiviral drug, Remdesivir is employed for the treatment of COVID19 patients. For 3 to 4 infected COVID-19 patients combination of drugs like Shufeng Jiedu Capsule (SFJDC), Lopinavir/Ritonavir a traditional Chinese medicine, Arbidol showed promising results $[65,69-$ 71]. Various other antiviral drugs are also being proposed for the treatment of COVID-19. Also, a few medicines are recommended for the treatment of COVID-19, which are given in Table 1 [70-72].

19

\subsection{Prevention and control strategies of COVID-}

The COVID-19 is spreading worldwide so rapidly, while the infection rate of the virus is very high with a low mortality rate. The infection rate is higher than MERS and SARS-CoVs. Older people and peoples

Table 2. Medicines recommended for COVID-19

\begin{tabular}{|c|c|}
\hline Medicines & Function \\
\hline Hydroxychloroquine & $\begin{array}{l}\text { Increase in the acidic levels of endosomes, prevents the endocytosis and stops the virus } \\
\text { to enter in the host cell }\end{array}$ \\
\hline Remdesivir & With the help of RNA template, it prevents the RNA reproduction \\
\hline $\begin{array}{l}\text { Lopinavir and } \\
\text { Ritonavir }\end{array}$ & Prevents RNA translation progression \\
\hline Ribavarin & Prevents mRNA capping and synthesis of viral RNA \\
\hline Darunavir & Stops the viral reproduction \\
\hline Favipiravir & $\begin{array}{c}\text { From the RNA template, it prevents the RNA reproduction and also, prevents RNA } \\
\text { translation progression }\end{array}$ \\
\hline Oseltamivir & Prevents RNA translation progression \\
\hline Arbidol & Prevents the outer membrane synthesis of the viral outer surface \\
\hline Monoclonal antibodies & Prevents the viral infection \\
\hline Umifenovir & Prevents virions synthesis through endosomal membrane \\
\hline
\end{tabular}


with lower immunity are at higher risk of death. To stop this rapid spreading of the virus isolation is needed. Till now there is no specific medicine and vaccine to combat the disease. Oxygen therapy and symptomatic care strategies are currently used to treat. Vaccination of prophylactic type is compulsory for the upcoming slowdown of COVID linked widespread and epidemic. In the community, the main measure for interrupting the transmission of the disease is the isolation of the infected individuals. For example in China, the decision was taken by Chinese medical authorities to quarantine suspected individuals for 14 days and isolated infected people [39]. Till now there is doubt of the virus's origin some says it came from animals like a bat [73], others say it came from snakes [74], so it is necessary to immediately stop eating these animals and stop coming in close contact with these animal's fluid and or tissues. People's education is also needed for spreading the disease and to get quick treatment. Individuals having symptoms like fever, shortness of breath, and or cough should immediately seek medical experts. For stopping the spread of the virus in large communities following things should be maintained like home isolation, mitigating social gatherings, temporary school closure, close nursing of symptomatic cases, wearing personal protective gears like a face mask, face shields, and carrying hand sanitizers, provision of life supports (e.g. oxygen supplier and mechanical ventilator), etc. In Wuhan city, Chinese authorities had taken lockdown measures seriously and strictly which stopped/slowed down the virus spreading [39, 75]. Ways of travel showed be minimized except for compulsory medical care. Setup of temperature scanning or checking is compulsory at the airport as well as at the border to recognize the suspected individuals. Further research with this COVID-19 virus is serious to find the outbreak source and to give proof of the upcoming epidemics [71]. Few vaccines are used nowadays. The vaccines that are administered by WHO are shown in Table 2 [76].

\section{Indian strategy for COVID-19 prevention and control}

The containment policies of India include detecting the positive cases and keeping them in isolation, social distancing, home quarantine, following additional medical guidance. Currently in India, 29,822,764 confirmed cases and 389,452 death cases have been reported, which is shown in Figure 6 [77]. Present protocols of treatment contain analyzes of Point-of-Care molecular tests and also real-time PCR diagnosis. The person who is at higher risk of COVID-19 such as forefront staffs and asymptomatic confirmed COVID cases are given Hydroxychloroquine or HCQ drug (An antimalarial drug). The Hydroxychloroquine medicine dozes are given as $400 \mathrm{mg}$ two times a day for one day and later $400 \mathrm{mg}$ once every week which will continue for seven weeks. Though, pregnant women and kids below fifteen years are not suitable for this drug [78].



The critical patients are given Hydroxychloroquine with Azithromycin drug. The dozes of Hydroxychloroquine and Azithromycin drug are $400 \mathrm{mg}$ two times a day for one day and later $200 \mathrm{mg}$ two times a day which will continue for four days, and $500 \mathrm{mg}$ one time a day which will continue for five days, respectively [79]. India introduced a mobile app named 'Arogya Setu' for tracing the activities of the people and also initiated plasma therapy to fight against the novel coronavirus. The government of India has initiated a complete lockdown and maintaining the social distance for the 
prevention of COVID-19 [78]. The lockdown schedule follows Phase-I: March 25 - April 14 [85][8o]; PhaseII: April 14 - May 3; Phase-III: May 4 - May 17; and Phase-IV: May 18 - May 31, 2020. In this pandemic situation, a supplementary test has been recommended as a rapid antibody test which is needed to keep in observation as the test reports are given after 7 to 10 days. As the laboratories are receiving a lot of samples for examining, pool testing is introduced in this placed so that the process does not take a longer time (five samples are examined at once). For in-vitro a famous drug for malaria Hydroxychloroquine showed hindering effect for COVID-19 for this reason this drug became the trial choice [81]. Although, the use of this drug or in combination with another macrolide drug already showed adverse cardiovascular outcomes for the QT period [81, 82]. Though, there is no proof that this drug is effective for this virus either alone or azithromycin combination, except there is a risk of ventricular arrhythmias has been shown by many researchers [83]. In India improving plasma therapy on various COVID-19 infected patients is done on those who were having a saturation of oxygen in the bloodless than $90 \%$ and rate of respiration greater than 30 breaths per minutes or having lungs infiltrations [84]. The selection of donors who were recovered after 28 days of having low viral load for plasma therapy are very specific i.e. they should be below 60 years old and should not have any pre-existing health conditions like hypertension, diabetes, and/or problems related to the heart [85, 86]. CSIR (Council of Scientific and Industrial Research of India already started working on more advanced vaccine development like the recombinant DNA vaccine and RNA vaccine for the C OVID-19 virus. The trials of $\mathrm{ACQH}$ are already being started by CSIR as it showed acceptable results in the case of the treatment of Dengue. This ACQH is an extraction of a plant which are found in areas like Madhya Pradesh, Jharkhand, and Gujrat Indian states [87]. Furthermore, Favipiravir drug clinical trial is also being done in India [88]. With the advancement of smartphone technology, India launched an App for both android and ios which is a useful intelligent software for awareness spreading of the coronavirus for the citizens of India [89]. This app provides various latest information like the total number of infected, the total number of the recovered, infected area, read zones, several peoples using this app near me within a radius of $50 \mathrm{~km}, 200 \mathrm{~km}$ as well as latest news and health services, etc. The software of the app uses smartphone Bluetooth and GPS to work properly, it tells the user whether he/she has come in contact with an infected individual or area by the database search of the country's confirmed case area. The infected individual's information is kept confidential because he/she does not face any social discrimination or rejection fear from the society peoples. Due to lockdown and different types of prevention, the new active cases of COVID-19 were able to control. Although, in the mid-week of September 2020, the new active COVID-19 positive cases increased it is observed that within mid-week February 2021, the new active cases decreased. Suddenly a huge number of new active COVID-19 cases was observed in the last week of March 2021 [77]. Simultaneously with COVID-19, a fungal infectious disease named "Black Fungus" was detected in the patients who recovered from COVID-19 [90].

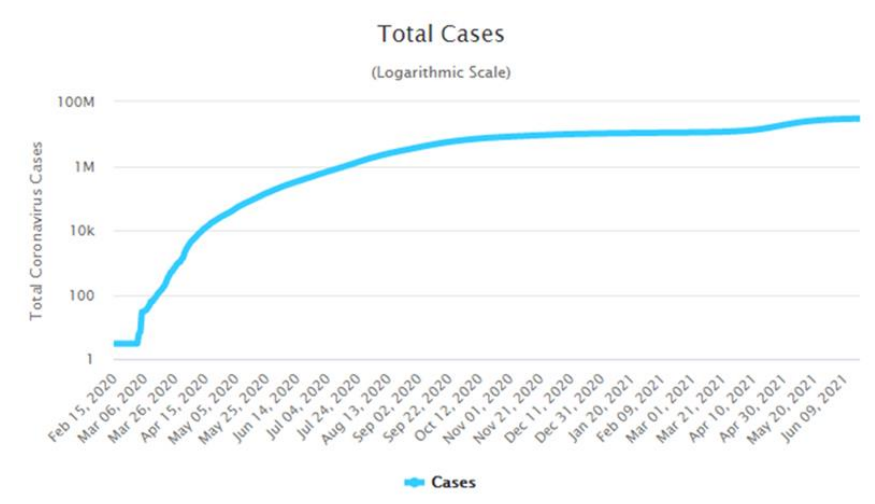

Figure 6. The present situation of COVID-19 in India [Worldometers, 18 June, 2021]

\section{Second wave of COVID-19 in India: Causes and effects}

Presently, India is going through a tough situation due to the second wave of COVID-19. As the days are passing by, the number of active cases is rising, and therefore India is going through a major medical crisis. There is a high demand for oxygen supplies but due to the medical crisis, India is unable to fulfill its oxygen demand. Few reasons for this deadly attack of COVID19 for the second time in India can't be neglected. As India is a third-world developing country with a huge population [91], there is a lack of proper implementation of rules and regulations. In 2020, people took COVID-19 seriously and they used to wear 
masks properly but as time passed there was a lack in the seriousness of proper way of wearing masks and sanitization. These are the basic habits that will help the public to fight against COVID-19 [92]. In maximum cases, it is noticed people are wearing single-layer cloth masks which increases the possibility of getting infected [93]. People should use double masking, a cloth mask above a three-layer mask, or wearing an N95 mask to avoid getting infected [94]. Due to the financial condition of Indian common people, individuals are bound to go to their respective workplace, therefore they have to avail the public transport which leads to increase in the number of active cases. Frontline workers like police, health workers, and other social workers, are working their sweat out are mostly getting affected due to the direct contact with more public. There is no growth of antibodies in the previously COVID-19 affected patients, due to which they are getting infected for the second time. In rural areas people share a common space to live in, therefore, when an infected person comes in contact with the non-infected person, for instant, using a common bathroom, the non-infected person gets infected. Indian government imposes few rules on social activities and occasions, but commoners were unable to maintain it in a proper way (improper use of mask, lack in the use of sanitizer and surface disinfected, and lack in proper social distancing). Due to the huge population, the Indian government is facing a huge challenge to vaccinate every individual, which leads to an insufficient vaccine, which is increasing the active number of cases in India. Although the Indian government (both central and state) took many initiatives but also several others NGOs started COVID-care support. IIEST-Shibpur, Howrah has started a COVID- care unit in their campus [95], they also initiated to vaccinate their employees, students, and their families.

\section{Conclusions}

The novel coronavirus is spreading worldwide very rapidly. The infection from this novel coronavirus is much higher concerning than MERS and SARS. From the Ro value is found out that the infection rate of SARS-CoV-2 is very high. Elderly people and those with weakened immune systems are at higher risk of dying and multi-organ failure. To cut the quick spread of the virus, social activities should be stopped and home lockdown and isolation are needed. Children below 15 years of age get no or less infected from this virus. Oxygen therapy and symptomatic care are the current treatment strategies. Vaccination of prophylactic type is needed for upcoming inhibition of COVID-19 related pandemic and epidemic.

\section{Supplementary files}

Supplementary file 1.

\section{Acknowledgments}

The authors would like to thank IIEST-Shibpur, Centrefor Healthcare Science and Technologylab, and thanks to Mrs. Nibedita Bardhan for language proof reading.

\section{Author contributions}

RB: Drafted the manuscript, Conceptualization, Collect the data. SD: Editing. ARC: Collect the data, Validation. PD: Editing, Supervision. All authors approved the final version of manuscripts.

\section{Conflict of interest}

The authors declare that there is no conflict of interest.

\section{Ethical declarations \\ Not applicable.}

\section{Financial Support}

No funding has been provided for this work. This paper is written for social cause and keeping in mind the present situations. It is written by the authors for their self-interest.

\section{References}

1. Hasöksüz M, Kiliç S, Saraç F. Coronaviruses and SARS-COV-2. Turk J Med Sci. 2020; 50(Si-1):549-56.

2. Singhal T. A Review of Coronavirus Disease-2019 (COVID-19). Indian J Pediatr. 2020; 87(4):281-6.

3. Kandeel M, Ibrahim A, Fayez M, Al-Nazawi M. From SARS and MERS CoVs to SARS-CoV-2: Moving toward more biased codon usage in viral structural and nonstructural genes. J Med Virol. 2020; 92(6):660-6.

4. World Health Organization. (2020). Coronavirus disease 2019 (COVID-19) : situation report, 40. World Health Organization. Available from: https://apps.who.int/iris/handle/10665/331351. 5. World Health Organization. (2020). Coronavirus disease 2019 (COVID-19) : situation report, 23. World Health Organization. Available from: https://apps.who.int/iris/handle/10665/330992. 6. Zhu N, Zhang D, Wang W, Li X, Yang B, Song J, et al. A Novel Coronavirus from Patients with Pneumonia in China, 2019. NEngl J Med. 2020; 382(8):727-33. 


\section{Barua et al.}

7. Huang C, Wang Y, Li X, Ren L, Zhao J, Hu Y, et al. Clinical features of patients infected with 2019 novel coronavirus in Wuhan, China. Lancet. 2020; 395(10223):497-506.

8. Atkinson B, Petersen E. SARS-CoV-2 shedding and infectivity. Lancet. 2020; 395(10233):1339-40.

9. Wu A, Peng Y, Huang B, Ding X, Wang X, Niu P, et al. Genome Composition and Divergence of the Novel Coronavirus (2019$\mathrm{nCoV})$ Originating in China. Cell Host Microbe. 2020; 27(3):3258.

10. Barua, Ranjit,et al. The Study of the Epidemiology and Clinical Features of the Novel Coronavirus (COVID-19). Epidemiological Research Applications for Public Health Measurement and Intervention, edited by Simon George Taukeni, IGI Global, 2021, pp. 25-39.

11. Uddin MB, Hasan M, Harun-Al-Rashid A, Ahsan MI, Imran MAS, Ahmed SSU. Ancestral origin, antigenic resemblance and epidemiological insights of novel coronavirus (SARS-CoV-2): Global burden and Bangladesh perspective. Infect Genet Evol. 2020; 84:104440.

12. Kucharski AJ, Althaus CL. The role of superspreading in Middle East respiratory syndrome coronavirus (MERS-CoV) transmission. Euro Surveill. 2015; 20(25):14-8.

13. Wu JT, Leung K, Leung GM. Nowcasting and forecasting the potential domestic and international spread of the 2019-nCoV outbreak originating in Wuhan, China: a modelling study. Lancet. 2020; 395(10225):689-97.

14. Yu WB, Tang GD, Zhang L, Corlett RT. Decoding the evolution and transmissions of the novel pneumonia coronavirus (SARSCoV-2 / HCoV-19) using whole genomic data. Zool Res. 2020; 41(3):247-57.

15. Guan WJ, Ni ZY, Hu Y, Liang WH, Ou CQ, He JX, et al. Clinical Characteristics of Coronavirus Disease 2019 in China. N Engl J Med. 2020; 382(18):1708-20.

16. Wu Z, McGoogan JM. Characteristics of and Important Lessons From the Coronavirus Disease 2019 (COVID-19) Outbreak in China: Summary of a Report of 72314 Cases From the Chinese Center for Disease Control and Prevention. Jama. 2020; 323(13):1239-42.

17. Chen N, Zhou M, Dong X, Qu J, Gong F, Han Y, et al. Epidemiological and clinical characteristics of 99 cases of 2019 novel coronavirus pneumonia in Wuhan, China: a descriptive study. Lancet. 2020; 395(10223):507-13.

18. Barreto ML, Teixeira MG, Carmo EH. Infectious diseases epidemiology. J Epidemiol Community Health. 2006; 60(3):1925 .

19. Ji W, Wang W, Zhao X, Zai J, Li X. Cross-species transmission of the newly identified coronavirus 2019-nCoV. J Med Virol. 2020; 92(4):433-40.

20. Wang B, Kovalchuk A, Li D, Rodriguez-Juarez R, Ilnytskyy Y, Kovalchuk I, et al. In search of preventive strategies: novel highCBD Cannabis sativa extracts modulate ACE2 expression in COVID-19 gateway tissues. Aging (Albany NY). 2020; 12(22):22425-44.

21. Bai Y, Yao L, Wei T, Tian F, Jin DY, Chen L, et al. Presumed Asymptomatic Carrier Transmission of COVID-19. Jama. 2020; 323(14):1406-7.

22. Berekaa MM. Insights into the COVID-19 pandemic: Origin, pathogenesis, diagnosis, and therapeutic interventions. Front Biosci (Elite Ed). 2021; 13:117-39.
23. Chu DKW, Pan Y, Cheng SMS, Hui KPY, Krishnan P, Liu Y, et al. Molecular Diagnosis of a Novel Coronavirus (2019-nCoV) Causing an Outbreak of Pneumonia. Clin Chem. 2020; 66(4):54955 .

24. Donia A, Hassan SU, Zhang X, Al-Madboly L, Bokhari H. COVID-19 Crisis Creates Opportunity towards Global Monitoring \& Surveillance. Pathogens. 2021; 10(3).

25. Bauch CT, Oraby T. Assessing the pandemic potential of MERS-CoV. Lancet. 2013; 382(9893):662-4.

26. Johansson MA, Quandelacy TM, Kada S, Prasad PV, Steele M, Brooks JT, et al. SARS-CoV-2 Transmission From People Without COVID-19 Symptoms. JAMA Netw Open. 2021; 4(1):e2035057. 27. Salian VS, Wright JA, Vedell PT, Nair S, Li C, Kandimalla M, et al. COVID-19 Transmission, Current Treatment, and Future Therapeutic Strategies. Mol Pharm. 2021; 18(3):754-71.

28. Gao Z, Xu Y, Sun C, Wang X, Guo Y, Qiu S, et al. A systematic review of asymptomatic infections with COVID-19. J Microbiol Immunol Infect. 2021; 54(1):12-6.

29. Harrison AG, Lin T, Wang P. Mechanisms of SARS-CoV-2 Transmission and Pathogenesis. Trends Immunol. 2020; 41(12):1100-15.

30. Umakanthan S, Sahu P, Ranade AV, Bukelo MM, Rao JS, Abrahao-Machado LF, et al. Origin, transmission, diagnosis and management of coronavirus disease 2019 (COVID-19). Postgrad Med J. 2020; 96(1142):753-8.

31. Wang D, Hu B, Hu C, Zhu F, Liu X, Zhang J, et al. Clinical Characteristics of 138 Hospitalized Patients With 2019 Novel Coronavirus-Infected Pneumonia in Wuhan, China. Jama. 2020; 323(11):1061-9.

32. Liu Y, Gayle AA, Wilder-Smith A, Rocklöv J. The reproductive number of COVID-19 is higher compared to SARS coronavirus. J Travel Med. 2020; 27(2).

33. Petersen E, Koopmans M, Go U, Hamer DH, Petrosillo N, Castelli F, et al. Comparing SARS-CoV-2 with SARS-CoV and influenza pandemics. Lancet Infect Dis. 2020; 20(9):e238-e44.

34. Elsayed SM, Hassanein OM, Hassan NHA. Influenza A(H1N1) virus infection and TNF-308, IL6, and IL8 polymorphisms in Egyptian population: a case-control study.J Basic Appl Zool. 2019; 80(1):61.

35. Petrosillo N, Viceconte G, Ergonul O, Ippolito G, Petersen E. COVID-19, SARS and MERS: are they closely related? Clin Microbiol Infect. 2020; 26(6):729-34.

36. Zhang S, Diao M, Yu W, Pei L, Lin Z, Chen D. Estimation of the reproductive number of novel coronavirus (COVID-19) and the probable outbreak size on the Diamond Princess cruise ship: A data-driven analysis. Int J Infect Dis. 2020; 93:201-4.

37. Schwartz DA. An Analysis of 38 Pregnant Women With COVID-19, Their Newborn Infants, and Maternal-Fetal Transmission of SARS-CoV-2: Maternal Coronavirus Infections and Pregnancy Outcomes. Arch Pathol Lab Med. 2020; 144(7):799-805.

38. Liu J, Liao X, Qian S, Yuan J, Wang F, Liu Y, et al. Community Transmission of Severe Acute Respiratory Syndrome Coronavirus 2, Shenzhen, China, 2020. Emerg Infect Dis. 2020; 26(6):1320-3. 39. Jing R, Kudinha T, Zhou ML, Xiao M, Wang H, Yang WH, et al. Laboratory diagnosis of COVID-19 in China: A review of challenging cases and analysis. J Microbiol Immunol Infect. 2021; 54(1):17-26. 


\section{Barua et al.}

40. Hu Z, Song C, Xu C, Jin G, Chen Y, Xu X, et al. Clinical characteristics of 24 asymptomatic infections with COVID-19 screened among close contacts in Nanjing, China. Sci China Life Sci. 2020; 63(5):706-11.

41. Meo SA, Alhowikan AM, Al-Khlaiwi T, Meo IM, Halepoto DM, Iqbal $\mathrm{M}$, et al. Novel coronavirus 2019-nCoV: prevalence, biological and clinical characteristics comparison with SARS-CoV and MERS-CoV. Eur Rev Med Pharmacol Sci. 2020; 24(4):20129.

42. Kang SJ, Jung SI. Age-Related Morbidity and Mortality among Patients with COVID-19. Infect Chemother. 2020; 52(2):154-64. 43. Gisondi P, S PI, Bordin C, Alaibac M, Girolomoni G, Naldi L. Cutaneous manifestations of SARS-CoV-2 infection: a clinical update. J Eur Acad Dermatol Venereol. 2020; 34(11):2499-504.

44. Rothe C, Schunk M, Sothmann P, Bretzel G, Froeschl G, Wallrauch C, et al. Transmission of 2019-nCoV Infection from an Asymptomatic Contact in Germany. N Engl J Med. 2020; 382(10):970-1.

45. Lai CC, Shih TP, Ko WC, Tang HJ, Hsueh PR. Severe acute respiratory syndrome coronavirus 2 (SARS-CoV-2) and coronavirus disease-2019 (COVID-19): The epidemic and the challenges. Int J Antimicrob Agents. 2020; 55(3):105924.

46. Yanez ND, Weiss NS, Romand JA, Treggiari MM. COVID-19 mortality risk for older men and women. BMC Public Health. 2020; 20(1):1742.

47. Bulut C, Kato Y. Epidemiology of COVID-19. Turk J Med Sci. 2020; 50(Si-1):563-70.

48. Xu X, Chen P, Wang J, Feng J, Zhou H, Li X, et al. Evolution of the novel coronavirus from the ongoing Wuhan outbreak and modeling of its spike protein for risk of human transmission. Sci China Life Sci. 2020; 63(3):457-60.

49. Xiao F, Tang M, Zheng X, Liu Y, Li X, Shan H. Evidence for Gastrointestinal Infection of SARS-CoV-2. Gastroenterology. 2020; 158(6):1831-3.e3.

50. Gavriatopoulou M, Ntanasis-Stathopoulos I, Korompoki E, Fotiou D, Migkou M, Tzanninis IG, et al. Emerging treatment strategies for COVID-19 infection. Clin Exp Med. 2021; 21(2):16779.

51. Kang H, Wang Y, Tong Z, Liu X. Retest positive for SARS-CoV2 RNA of "recovered" patients with COVID-19: Persistence, sampling issues, or re-infection? J Med Virol. 2020; 92(11):22635 .

52. Li H, Liu SM, Yu XH, Tang SL, Tang CK. Coronavirus disease 2019 (COVID-19): current status and future perspectives. Int J Antimicrob Agents. 2020; 55(5):105951.

53. Hani C, Trieu NH, Saab I, Dangeard S, Bennani S, Chassagnon G, et al. COVID-19 pneumonia: A review of typical CT findings and differential diagnosis. Diagn Interv Imaging. 2020; 101(5):263-8.

54. Liu J, Xie W, Wang Y, Xiong Y, Chen S, Han J, et al. A comparative overview of COVID-19, MERS and SARS: Review article. Int J Surg. 2020; 81:1-8.

55. Allotey J, Stallings E, Bonet M, Yap M, Chatterjee S, Kew T, et al. Clinical manifestations, risk factors, and maternal and perinatal outcomes of coronavirus disease 2019 in pregnancy: living systematic review and meta-analysis. Bmj. 2020; 370:m3320.

56. Baig AM. Neurological manifestations in COVID-19 caused by SARS-CoV-2. CNS Neurosci Ther. 2020; 26(5):499-501.
57. Peng M, Dai J, Sugali CK, Rayana NP, Mao W. The Role of the Ocular Tissue in SARS-CoV-2 Transmission. Clin Ophthalmol. 2020; 14:3017-24.

58. Aljondi R, Alghamdi S. Diagnostic Value of Imaging Modalities for COVID-19: Scoping Review. J Med Internet Res. 2020; 22(8):e19673.

59. Ai T, Yang Z, Hou H, Zhan C, Chen C, Lv W, et al. Correlation of Chest CT and RT-PCR Testing for Coronavirus Disease 2019 (COVID-19) in China: A Report of 1014 Cases. Radiology. 2020; 296(2):E32-e40.

60. Song Y, Zhang M, Yin L, Wang K, Zhou Y, Zhou M, et al. COVID-19 treatment: close to a cure? A rapid review of pharmacotherapies for the novel coronavirus (SARS-CoV-2). Int J Antimicrob Agents. 2020; 56(2):106080.

61. Devaux CA, Rolain JM, Raoult D. ACE2 receptor polymorphism: Susceptibility to SARS-CoV-2, hypertension, multi-organ failure, and COVID-19 disease outcome. J Microbiol Immunol Infect. 2020; 53(3):425-35.

62. Palacios Cruz M, Santos E, Velázquez Cervantes MA, León Juárez M. COVID-19, a worldwide public health emergency. Rev Clin Esp. 2020; 221(1):55-61.

63. Holshue ML, DeBolt C, Lindquist S, Lofy KH, Wiesman J, Bruce H, et al. First Case of 2019 Novel Coronavirus in the United States. N Engl J Med. 2020; 382(10):929-36.

64. Meo SA, Klonoff DC, Akram J. Efficacy of chloroquine and hydroxychloroquine in the treatment of COVID-19. Eur Rev Med Pharmacol Sci. 2020; 24(8):4539-47.

65. Wang M, Cao R, Zhang L, Yang X, Liu J, Xu M, et al. Remdesivir and chloroquine effectively inhibit the recently emerged novel coronavirus (2019-nCoV) in vitro. Cell Res. 2020; 30(3):269-71.

66. Leneva I, Kartashova N, Poromov A, Gracheva A, Korchevaya E, Glubokova E, et al. Antiviral Activity of Umifenovir In Vitro against a Broad Spectrum of Coronaviruses, Including the Novel SARS-CoV-2 Virus. Viruses. 2021; 13(8).

67. Harapan H, Itoh N, Yufika A, Winardi W, Keam S, Te H, et al. Coronavirus disease 2019 (COVID-19): A literature review. J Infect Public Health. 2020; 13(5):667-73.

68. Nguyen AA, Habiballah SB, Platt CD, Geha RS, Chou JS, McDonald DR. Immunoglobulins in the treatment of COVID-19 infection: Proceed with caution! Clin Immunol. 2020; 216:108459. 69. Zhu Z, Lu Z, Xu T, Chen C, Yang G, Zha T, et al. Arbidol monotherapy is superior to lopinavir/ritonavir in treating COVID19. J Infect. 2020; 81(1):e21-e3.

70. Singh AK, Singh A, Singh R, Misra A. Remdesivir in COVID-19: A critical review of pharmacology, pre-clinical and clinical studies. Diabetes Metab Syndr. 2020; 14(4):641-8.

71. Rosa SGV, Santos WC. Clinical trials on drug repositioning for COVID-19 treatment. Rev Panam Salud Publica. 2020; 44:e40.

72. Hung IF, Lung KC, Tso EY, Liu R, Chung TW, Chu MY, et al. Triple combination of interferon beta- 1 b, lopinavir-ritonavir, and ribavirin in the treatment of patients admitted to hospital with COVID-19: an open-label, randomised, phase 2 trial. Lancet. 2020; 395(10238):1695-704.

73. Shereen MA, Khan S, Kazmi A, Bashir N, Siddique R. COVID19 infection: Emergence, transmission, and characteristics of human coronaviruses. J Adv Res. 2020; 24:91-8. 


\section{Barua et al.}

74. Tiwari R, Dhama K, Sharun K, Iqbal Yatoo M, Malik YS, Singh $\mathrm{R}$, et al. COVID-19: animals, veterinary and zoonotic links. Vet $\mathrm{Q}$. 2020; 4O(1):169-82.

75. Sun GQ, Wang SF, Li MT, Li L, Zhang J, Zhang W, et al. Transmission dynamics of COVID-19 in Wuhan, China: effects of lockdown and medical resources. Nonlinear Dyn. 2020:1-13.

76. Hodgson SH, Mansatta K, Mallett G, Harris V, Emary KRW, Pollard AJ. What defines an efficacious COVID-19 vaccine? A review of the challenges assessing the clinical efficacy of vaccines against SARS-CoV-2. Lancet Infect Dis. 2021; 21(2):e26-e35.

77. Coronavirus Cases - Worldometer. Retrieved June 18, 2021. Available from: https://www.worldometers.info/coronavirus/country/india.

78. Ministry of Health and Family Welfare. Government of India. Revised advisory on the use of Hydroxychloroquine (HCQ) as prophylaxis for COVID-19 infection (in supersession of previous advisory dated 23rd March, 2020). Available from: https://www.mohfw.gov.in/pdf/Revisedadvisoryontheuseofhydr oxychloroquineasprophylaxisforSARSCOVID19infection.pdf.

79. Fiolet T, Guihur A, Rebeaud ME, Mulot M, Peiffer-Smadja N, Mahamat-Saleh Y. Effect of hydroxychloroquine with or without azithromycin on the mortality of coronavirus disease 2019 (COVID-19) patients: a systematic review and meta-analysis. Clin Microbiol Infect. 2021; 27(1):19-27.

80. Deep Singh K, Goel V, Kumar H, Gettleman J. India, Day 1: World's Largest Coronavirus Lockdown Begins. The New York Times. Available

https://www.nytimes.com/2020/03/25/world/asia/indialockdown-coronavirus.html.

81. Elavarasi A, Prasad M, Seth T, Sahoo RK, Madan K, Nischal N, et al. Chloroquine and Hydroxychloroquine for the Treatment of COVID-19: a Systematic Review and Meta-analysis. J Gen Intern Med. 2020; 35(11):3308-14.

82. Giudicessi JR, Noseworthy PA, Friedman PA, Ackerman MJ. Urgent Guidance for Navigating and Circumventing the QTcProlonging and Torsadogenic Potential of Possible Pharmacotherapies for Coronavirus Disease 19 (COVID-19). Mayo Clin Proc. 2020; 95(6):1213-21.

83. Arshad S, Kilgore P, Chaudhry ZS, Jacobsen G, Wang DD, Huitsing $\mathrm{K}$, et al. Treatment with hydroxychloroquine, azithromycin, and combination in patients hospitalized with COVID-19. Int J Infect Dis. 2020; 97:396-403.

84. Agarwal A, Mukherjee A, Kumar G, Chatterjee P, Bhatnagar T, Malhotra P. Convalescent plasma in the management of moderate covid-19 in adults in India: open label phase II multicentre randomised controlled trial (PLACID Trial). Bmj. 2020; 371:m3939.

85. Rajendran K, Krishnasamy N, Rangarajan J, Rathinam J, Natarajan M, Ramachandran A. Convalescent plasma transfusion for the treatment of COVID-19: Systematic review. J Med Virol. 2020; 92(9):1475-83.

86. Kumar P, Sah AK, Tripathi G, Kashyap A, Tripathi A, Rao R, et al. Role of ACE2 receptor and the landscape of treatment options from convalescent plasma therapy to the drug repurposing in COVID-19. Mol Cell Biochem. 2021; 476(2):553-74.

87. Council of Scientific \& Industrial Research. COVID-19 Treatment: ACQH, Convalescent Plasma Trials to Begin Soon, Says CSIR DG.

Available from: https://www.csir.res.in/slider/covid-19treatment-acqh-convalescent-plasma-trials-begin-soon-says-csirdg

88. Joshi S, Parkar J, Ansari A, Vora A, Talwar D, Tiwaskar M, et al. Role of favipiravir in the treatment of COVID-19. Int J Infect Dis. 2021; 102:501-8.

89. Basu S. Effective Contact Tracing for COVID-19 Using Mobile Phones: An Ethical Analysis of the Mandatory Use of the Aarogya Setu Application in India. Camb Q Healthc Ethics. 2020; 30(2):262-71.

90. Dyer O. Covid-19: India sees record deaths as "black fungus" spreads fear. Bmj. 2021; 373:n1238.

91. World Population Review. Available from: https://worldpopulationreview.com/countries/india-population. 92. Fouladi Dehaghi B, Ghodrati-Torbati A, Teimori G, Ibrahimi Ghavamabadi L, Jamshidnezhad A. Face masks vs. COVID-19: a systematic review. Invest Educ Enferm. 2020; 38(2).

93. MacIntyre CR, Dung TC, Chughtai AA, Seale H, Rahman B. Contamination and washing of cloth masks and risk of infection among hospital health workers in Vietnam: a post hoc analysis of a randomised controlled trial. BMJ Open. 2020; 10(9):e042045.

94. Yasri S, Wiwanitkit V. Double-surgical-mask-with-slit and COVID-19 prevention. Endoscopy. 2021; 53(1):96.

95. Chowdhury S. IIEST sets up Covid-care unit on campus. Telegraph India. Available from: https://www.telegraphindia.com/west-

bengal/calcutta/coronavirus-outbreak-iiest-sets-up-covid-careunit-on-campus/cid/1813275. 